\title{
Be Empathic! The Influence of Empathy on Attitude Formation in the German Refugee Debate
}

\author{
Julia Weber $^{1} \&$ Marc-André Reinhard ${ }^{1}$ \\ ${ }^{1}$ Department of Psychology, University of Kassel, Kassel, Germany \\ Correspondence: Julia Weber, Department of Psychology, University of Kassel, Kassel, Germany. Tel: \\ 49-157-3798-4784. E-mail: j.weber93@icloud.com
}

Received: November 14, 2015

Accepted: December 10, 2016 Online Published: December 23, 2016

doi:10.5539/ijps.v9n1p62

URL: http://dx.doi.org/10.5539/ijps.v9n1p62

\begin{abstract}
The study was conducted to investigate the elaboration and memorisation of the emotionally charged refugee debate with reference to the possible influences of empathic feelings, political attitude and mood. It was hypothesised that empathy towards refugees correlates positively with advanced elaboration and memorisation of the refugee debate. Participants' personal empathy was assessed through a self-report questionnaire which differentiates between four distinct dimensions of empathy. Afterwards, participants listened to an interview with a politician from a German populist party about refugee policies concluding with a test about the content. As expected, the results revealed a positive correlation between the empathy dimensions' Fantasy and Personal Distress and the correct answers of the open-ended question test. The Fantasy dimension of empathy was significantly correlated with the elaboration and memorisation of the extreme and populist positions in the refugee debate. Important practical implications as well as limitations of the study were discussed.
\end{abstract}

Keywords: elaboration, empathy, memorisation, political debate

\section{Introduction}

The refugee debate is polarising and emotionally charged in Germany and Europe. As the number of people seeking asylum is on the rise, many feel empathic for the refugees' plight and try to be welcoming towards them. The political debate is loud and angry but do people still listen to each other properly? Discussions are usually accompanied by strong emotions like empathic feelings and fury, as it can be seen on Internet forums where arguments about the current refugee situation regularly become offensive and abusive. Possible consequences of these kinds of emotionally charged debates can be seen in the United Kingdom where a majority voted to leave the European Union in the referendum. After the BREXIT many British people were surprised about the consequences and regretted this decision.

In the context of the refugee debate, the emotional involvement of empathy is undoubtedly an extremely important matter. There is evidence for the link between empathy and helping behaviour (Coke, Batson, \& McDavis, 1978). Empathy enables people to imagine the refugees' needs who had to escape from their plight and life-threatening circumstances. However, is it possible to follow the political debate analytically whilst feeling empathic emotions or does empathy even support analytical processing of the debate?

We would state that it is necessary to understand what populist parties like the AfD in Germany are claiming because this party emerged from the latest Landtagswahlen with significant gains: $15.1 \%$ in Baden-Württemberg, $12.6 \%$ in Rhineland Palatinate and 24.3\% in Saxony-Anhalt (Der Bundeswahlleiter, 2016). For these reasons, this study deals with the possible influence of empathy on elaboration and memorisation of information in the context of the current political topic of refugees.

In the following, we illustrate existing literature on empathy as well as possible influences of empathy on the elaboration and memorisation of information.

\subsection{The Concept of Empathy}

Empathy is a construct which is valued positively by most people. There are even certain disorders such as autism (Baron-Cohen \& Wheelwright, 2004) and schizophrenia (Bora, Gökçen, \& Veznedaroglu, 2008) which conclude that people with these disorders are incapable of feeling empathic emotions or taking someone else's perspective. 
Obviously, empathy is an important basic skill needed for interpersonal relationships and therefore for a functioning society.

Empathy has a wide range of definitions (Cuff, Brown, Taylor, \& Howat, 2014). In 1909 Edward Titchener coined the word empathy from the German translation Einfühlung (as cited in Stanghellini \& Rosfort, 2013), since at that time there was no common consensus for one definition. Cuff et al. (2014) reviewed different definitions of empathy from various authors and tried to determine similarities and differences between them. In the following, we point out some aspects which are relevant to obtain a clear understanding of the construct and for further investigations.

Past researches on empathy focussed either on cognitive or emotional processes of empathy "a cognitive, intellectual reaction on the one hand (an ability simply to understand the other person's perspective), and a more visceral, emotional reaction on the other" (Davis, 1983, p. 113).

In the $20^{\text {th }}$ century a new line of research arose which assumed that empathy contains an interactive connection between emotional and cognitive processes. Nowadays, there is evidence and it is generally agreed that there is an interaction between cognitive and emotional processes of empathy (Coke et al., 1978; Cuff et al., 2014).

Derived from this new line of research, Davis (1980) designed the Interpersonal Reactivity Index (IRI); an instrument to measure individual differences of empathy based on a multidimensional approach. The IRI includes four dimensions which can be distinguished from each other. There are two cognitive scales: The Perspective-Taking scale (e.g., I believe that there are two sides to every question and try to look at them both) that measures the tendency to take the perspective of someone else and the Fantasy scale (e.g., After seeing a play or movie, I have felt as though I were one of the characters) that assesses the tendency to put oneself in the thoughts and feelings of fictitious characters. There are also two emotional scales: The Empathic Concern scale (e.g., I am often quite touched by things that I see happen) which measures empathic feelings for unfortunate others and the Personal Distress scale (e.g., I sometimes feel helpless when I am in the middle of a very emotional situation) which assesses egoistic feelings of distress in tense interpersonal situations (Davis, 1983).

Irrespective of the four distinctive dimensions of empathy, there is no consensus about one sum score of empathy. The four dimensions are not intended to be built as a total sum score and even the attempt to build a sum score of the dimensions Fantasy, Empathic Concern and Perspective Taking is not covered.

Considering empathy as a trait is a prerequisite to measure individual differences in dispositional empathy scores. However, there is research showing situational effects of salience (Batson, Klein, Highberger, \& Shaw, 1995) or perceived similarity on empathy (Xu, Zuo, Wang, \& Han, 2009). For example, Xu et al. (2009) investigated the different neural mechanisms of the relationship between empathy and the same racial group. There was greater activation in the anterior cingulate cortex if a person observed a subject from the in-group and in pain, than a subject from the out-group and in pain. Nevertheless, there is a wide range of evidence across different disciplines which strongly supports the approach that empathy has the characteristics of a trait (Cuff et al., 2014; Davis \& Franzoi, 1991), even if situational factors can influence empathic emotions. For further investigations we follow the approach of empathy as a trait.

\subsection{Bright Side of Empathy}

"From an adaptive-evolutionary perspective, it can be assumed that emotion has a privileged role in biasing the allocation of attentional resources toward events with particular significance for an organism's motivational state" (Vuilleumier, Armony, \& Dolan, 2003).

There is research showing a positive influence of empathy on elaboration and memorisation of information.

Based on the dual-process theories, there are two systems of processing, an emotional system and a cognitive system, which are linked. Caused by the limitation of cognitive resources, the emotional system process most of the information (Epstein, 1991). As stated before, empathy contains emotional and cognitive processes as well.

In this context Vuilleumier et al. (2003) reported that emotions have a positive influence on cognitive processing by leading to attention. Attentional selection is obligatory to elaborate cognitively, caused by the limited cognitive resources. The authors have shown, that "both attention and emotion involve distributed neural networks of highly interactive cortical and subcortical brain regions that are in a position to regulate processes related to perception, action, and memory" (Vuilleumier et al., 2003). According to this line empathic emotions could be the motor for cognitive processing and so for proper elaboration and memorisation of information. 
Anderson and Phelps (2001) investigated the underlying physiological mechanism of the link between emotional stimuli and attentional selection. The authors could demonstrate that emotional stimuli lead to an increase activation of the amygdala which in turn leads to advanced perception of these stimuli.

Moreover, Anderson (2005) demonstrated the influence of emotional stimuli with regard to the Rapid Serial Visual Presentations task (RSVP-task) in which participants usually have an attentional blink of the second target after a rapid presentation of distractors. If the second target was an emotional stimulus, the attentional blink was decreased. In addition to this, Yerkes and Dodson have shown that emotional arousal and stress are not always obstructive to process information. In fact, it was discovered that under middle stress conditions the learning process was at its highest (Yerkes \& Dodson, 1908).

\subsection{Dark Side of Empathy}

"Will the world end up rescuing Somalia while ignoring the Sudan mainly because the former proves more photogenic?" (Isaacson, 1992).

There is also literature showing the negative influence of empathy on elaboration and memorisation of information. As empathy leads to physiological arousal (Krebs, 1975), it is possible that physiological arousal, induced by empathic emotions, interferes negatively with processing information (Cassady \& Johnson, 2002).

As there are two kinds of processing, emotions might inhibit calm reasoning and analytical thinking based on cognitions.

Bodenhausen, Sheppard, and Kramer (1994) showed that negative emotions such as anger cause stereotypical judgements and the use of heuristics.

Furthermore, Tsoudis (2002) showed how empathy can be easily manipulated. When participants were tested as a mock jury in criminal trials, there was a link between the criminal's display of emotions and the jury's empathy which in turn, had an effect on the participants' decision-making. Additionally, Batson et al. (1995) have shown that empathy is mostly felt for individuals and for those people who are accessible through media or proximity.

In addition, there were studies which examined the situational effect of similarity on empathy, as stated before. Johnson et al. (2002) showed that similarity induced empathy even influences a decision-making task in legal contexts. White participants had more empathy for white defenders and allocated more lenient punishments. It could therefore be argued that there are sound reasons for basing our legal system on cognitive rationality and not on empathy. Batson et al. (1995) showed that the very broad principal of justice, which is an important maxim of our society and based on rational reasoning, becomes unimportant in comparison to empathy. The authors examined the connection between empathy induced altruism and moral judgement. It was shown that empathy can lead to a violation of moral principles, such as justice, when someone has empathic emotions for another person (Batson et al., 1995).

Although the work on the dark side of empathy would predict a negative correlation between empathy and the elaboration and memorisation of extreme populist arguments in the refugee debate, we would assume a positive correlation. In accordance with the presented theoretical reasoning of Vuilleumier et al. (2003) that, in particular, emotional stimuli lead to selective attention and cognitive processing, we state a positive correlation between empathy and elaboration and memorisation of extreme populist arguments in the refugee debate. Especially in regard to the need of cognitive motivation and attention to elaborate extreme populist position, which should be induced by empathy, stresses our expectation. In other words, empathy will increase the probability to attentively listen also to extreme populist information.

\section{Methods}

\subsection{Participants}

Giving expected effect size of $d=0.3$ the intended sample size, defined by g Power (Cohen, 1988) embraces 60 participants. Thus, the study was finished once 60 persons had participated. Three participants had to restart the study because the programme crashed during the first attempt. Only the second and complete data of these three participants were analyzed.

All participants were recruited from the campus of the University of Kassel. 41 women, 18 men and one participant, who selected "prefer not to say" participated in the study. The age of the participants ranged from 19 to 38 years $(M=24.18, S D=3.56)$. The study took place in the laboratory in the Department of Psychology at the University of Kassel. 


\subsection{Procedure and Material}

The study was conducted on a computer. The study started with an informed consent form indicating that participation was voluntarily and all information provided would remain anonymous. Each participant consented to the study.

At the beginning, participants had to answer demographical questions about age, gender, level of education degree and profession.

Afterwards, participants had to complete the Interpersonal Reactivity Index (Davis, 1980) questionnaire, in the German version by Keller and Pfattheicher (2013), in order to identify individual differences of empathy.

As stated in the theoretical section, Davis defined empathy as a multidimensional approach. The questionnaire covers 28 -items, 7 items on each scale. The cognitive scales', Perspective-Taking and Fantasy, and the emotional scales', Empathic Concern and Personal Distress, had to be assessed on a five-point Likert scale ranging from "Does not describe me well" to "Describes me very well". The IRI scales have been proven to be valid and reliable (Davis, 1983). The internal reliabilities found for the scales were similar to Davis' (Fantasy: Cronbach's $\alpha=.744$, Empathic Concern: Cronbach's $\alpha=.764$, Perspective-Taking: Cronbach's $\alpha=.770$, Personal Distress: Cronbach's $\alpha=$.787).

Next, as a control variable we assessed participant's attitude toward xenophobia and the devaluation of asylum seekers using five items from the Mitte-Studie 2014 (Decker, Kiess, \& Brähler, 2014) questionnaire. The items were "Foreigners only come to Germany to take advantage of our social system", "If there is a scarcity of jobs, foreigners should be sent back to their home country", "Because of the many foreigners, Germany is dangerously foreign dominated", "The state should be generous when examining requests for asylum", "Most of the applicants for asylum do not fear persecution in their home country".

All answers were giving on a five-point Likert scale ranging from "totally disagree" to "totally agree".

Afterwards, the topic refugee debate was introduced. Participants saw a short video about the refugee camp in Idomeni, Greece, March 2016 (Flüchtlinge $\diamond$ Frontex $\diamond$ Freihandelsabkommen TTIP und CETA, 2016; https://www.youtube.com/watch?v=1uDVIj2g-As). The video is a report from the German news Tagesschau and lasted approximately 1.35 minutes. The video includes pictures of the camp and illustrates the precarious situation of refugees on the run. The participants could see the inhumane living conditions: tents on muddy ground, a dirty environment and rain soaking the clothes and tents. There is an off-screen voice commenting on the pictures of the camp. The voice is reporting about the cold temperatures which pose a severe threat to young children. Three refugees from the camp are interviewed and explain their desperate situation. For example, one of them mentions his concerns about his family and his hope for a safe place to live.

Afterwards, the participants' mood was measured by the "Positive and Negative Affect Schedule" PANAS (Watson, Clark, \& Tellegen, 1988) questionnaire, translated into German by Krohne, Egloff, Kohlmann, and Tausch (1996), in order to control if negative feelings (distressed, upset, guilty, scared, hostile, irritable, ashamed, nervous, jittery, afraid extended by the item "stress"), induced by the video of the camp, had an influence on later elaboration and memorisation of information, Cronbach's $\alpha=.776$.

During the next stage, the extreme populist arguments were presented to the participants. Participants watched a video showing an interview with Frauke Petry, the AFD party leader, at an AFD party convention in Hannover, Germany. The video lasted 3.18 minutes. In the interview, Petry expresses her ideas about how refugee policies should change (Phoenix, 2015; https://www.youtube.com/watch?v=GgVGfwejp2o). The interviewer asks Frauke Petry two questions. The first one deals with a controversial statement by the AfD Party-member Marcus Pretzell about boarder policies. Frauke Petry answers "Borders have to be protected even through the use of firearms in case of necessity as a last resort". The second question is about Frauke Petry's attempt to change the right to asylum. Petry condemns that "Angela Merkel invites all migrants of the world to Germany"; Petry wants to "as legislator, change the right to asylum". Her justification is that "the acceptance rate of politically persecuted people is $2 \%$ " and therefore, "the advantage of applying for asylum near to the native country is that the decisive factor for migration is the necessity of political protection and not the incentive systems".

After the video, participants had to answer five items (upset, hostile, irritable, nervous, stressed; Cronbach's $\alpha$ $=.564$ ) again in order to control whether the mood caused by the interview had an influence on their elaboration and memorisation of the content.

Afterwards, participants had to answer five questions on the remarks in the video in order to measure the elaboration and memorisation of the content. The first question in the study referred to the first question asked by the interviewer: "Which position does Frauke Petry represent with respect to the discussion started by Marcus 
Pretzell?". The interviewer's second question was divided into four questions in the study to ensure that participants were able to assign the correct answer. Participants were asked "What complaints does Frauke Petry make against Angela Merkel?", "What proposals does Frauke Petry make so that asylum seekers have to apply for asylum abroad?", "What percentage of the acceptance rate of politically persecuted people does Frauke Petry state?", and "According to Frauke Petry what is the advantage of applying for asylum close to the native country?".

Subsequently, participants were asked the same five questions but this time phrased in a closed question style. Following the same format as the open-ended questions, there was only one correct answer and four distractors to minimise the chance of randomly finding the correct answer. Each distractor was similar to the correct answer and was formulated in a way close to the programme of the AfD Party. This second test was included as a control test. Giving that these questions might be influenced by the OEQT, we would expect the same but smaller effect on this test.

Finally, there was a control check about the information provided by a news-ticker during the interview in order to control whether the participants had paid attention to this rather than listening to the interview.

\section{Results}

A positive correlation between empathy and the elaboration and memorising of the interview was predicted.

All analysis ran with $N=60$ participant.

In order to initially investigate the construct of empathy, the inter-correlations of the four dimensions were examined (Table 1). A similar pattern emerged as was reported by Davis (1980).

Furthermore, the relationship of the dimensions of empathy with the control variables attitude and mood were examined: attitude was negatively significantly correlated to the Fantasy scale $(r=-.375, p=.003)$, as well as to the Perspective-Taking $(r=-.294, p=.023)$ and the Empathic Concern $(r=-.301, p=.020)$ scales. The mood after watching the interview was positively significantly correlated to the Fantasy scale $(r=.271, p=.036)$ and the Empathic Concern scale $(r=.289, p=.025)$. The mood was negatively significantly correlated with the attitude $(r=-.569, p<.01)$.

Correct answers given in the five questions from the Open Ended Question Test (OEQT) were calculated to a sum score. Correct answers giving in the five questions from the Multiple Choice Question Test (MCQT) were calculated to a sum score as well. Rater agreed in $94,33 \%$ of coding the correct answers from the OEQT (Cohen's kappa $=.89)$. Participants correct answers given in the OEQT $(M=2.47, S D=1.21)$ correlated significantly with the correct answers given in the MCQT $(M=4.07, S D=.95), r(60)=.675, p<.01$. On average, participants had significantly higher test scores in the MCQT than in the OEQT, $t(59)=13.684, p<.01$.

Correlations between the dimensions of empathy and the correct test results from the OEQT and the MCQT can be seen in Table 1.

Table 1. Correlations between the dimensions of empathy and the correct answers from the OEQT and MCQT

\begin{tabular}{lccccccc}
\hline & 2. & 3. & 4. & 5. & 6. & 7. & 8. \\
\hline 1. OEQT & $.675^{* *}$ & $.309^{*}$ & .092 & -.118 & $.280^{*}$ & .035 & .037 \\
2. MCQT & - & .241 & .189 & .030 & .116 & .066 & .094 \\
3. FS & & - & $.519 *$ & .208 & .165 & $-.375^{* *}$ & $.271^{*}$ \\
4. EC & & & - & $.524^{* *}$ & .212 & $-.301^{*}$ & $.289^{*}$ \\
5. PT & & & & - & -.112 & $-.294^{*}$ & .173 \\
6. PD & & & & & - & .153 & -.062 \\
7. Attitude & & & & & - & $-.569 * *$ \\
8. Mood & & & & & & & - \\
\hline $\mathrm{p}<.05, * * \mathrm{p}<.01$. & & & & & & &
\end{tabular}

$\mathrm{OEQT}=$ correct answers in the open ended question test

MCQT $=$ correct answers in the multiple choice question test

$\mathrm{FS}=$ Fantasy scale, $\mathrm{EC}=$ Empathic Concern, $\mathrm{PT}=$ Perspective-taking scale, $\mathrm{PD}=$ Personal Distress 
As expected the results from the OEQT were significantly positively correlated with the Fantasy scale $(r=.309, p$ $=.02)$ and with the Personal Distress scale $(r=.280, p=.03)$, indicating that more empathy leads to more correct answers. There was no significant correlation with the Empathic Concern scale $(r=.092, p=.482)$ and the Perspective-Taking scale $(r=-.118, p=.370)$.

To further test our hypothesis a first multiple linear regression was calculated for the results from the OEQT as the dependent variable and all four dimensions of empathy as predictor variables. The results showed the overall model to be significant, $F(4,60)=2.903, p=.030\left(R^{2}=.174, R^{2}\right.$ adj $\left.=.114\right)$. In this model, only the Fantasy scale had a significant influence on the results from the OEQT, $p=.026$. The other three predictors were found to be not significant (Table 2).

Table 2. Regression analysis for the results from the OEQT, including the dimensions of empathy

\begin{tabular}{lccccc}
\hline & $\mathrm{b}$ & $\mathrm{SE}$ & $\beta$ & $\mathrm{T}$ & Sig. \\
\hline Constant & .575 & 1.492 & & .385 & .701 \\
FS & .092 & .040 & .329 & 2.283 & .026 \\
EC & -.019 & .056 & -.056 & -.328 & .744 \\
PT & -.046 & .052 & -.132 & -.882 & .382 \\
PD & .066 & .039 & .223 & 1.711 & .093 \\
\hline
\end{tabular}

Note. $\mathrm{FS}=$ Fantasy scale, $\mathrm{EC}=$ Empathic Concern, $\mathrm{PT}=$ Perspective-taking scale, $\mathrm{PD}=$ Personal Distress.

Including our control variables attitude and mood does not chance the result. The Fantasy scale had also a significant influence, $p=.023$, on the correct answers from the OEQT, while the attitude and participant's mood had no significant influence on the dependent variable.

The results from the MCQT were positively but not significantly correlated with the Fantasy scale $(r=.241, p$ $=.064)$. There were no significant correlations between the results from the MCQT and the Empathic Concern $(r$ $=.189, p=.148)$, Perspective-Taking $(r=.030, p=.823)$ and Personal Distress $(r=.116, p=.379)$ scales.

In a next step, a regression was calculated for the results from the MCQT as the dependent variable and the four dimensions of empathy as predictors. The overall model was not significant, $F(4,60)=1.047, p=.392\left(R^{2}=.071\right.$, $R_{\text {adj }}^{2}=.003$ ).

Additional it was examined whether participants' attitude, as well as the mood after watching the interview, had a significant influence on the results from the MCQT.

None of the stated predictors had a significant influence on the results from the MCQT.

\section{Discussion}

The study dealt with the influence of empathy on elaboration and memorisation of emotionally loaded political debates with regard to the refugee situation. As previously stated, we expected that there would be a positive correlation between empathy and the elaboration and memorisation of Frauke Petry's statements given during the interview. As predicted, higher scores on the dimensions' Fantasy and Personal Distress were significantly positively correlated with the correct answers given in the OEQT. In this study, empathy seems to work as a motor to stress the personal importance of the debate which then results in listening attentively (Vuilleumier et al., 2003) and proper elaboration and memorisation.

A possible explanation for the significant results in the OEQT but non-significant results in the MCQT could be that the MCQT was too simple to answer. This assumption derives support from the significantly higher average of correct answers in the MCQT in comparison to the average of correct answers in the OEQT. Another possible explanation could be that the MCQT was always after participants answers of the OEQT. The OEQT may have helped to recall the correct answer from the MCQT.

Xenophobic attitudes were negatively correlated to all dimensions of empathy, except the Personal Distress dimension. With regard to these results, it is important to highlight that empathy was measured as a dispositional trait and not as an empathic state for refugees.

By running a regression on the results from the OEQT, Fantasy scale was the only predictor which had a significant influence on the dependent variable. Consequently, mood and attitude had no influence on 
elaboration and memorisation. Yet again, the results from the MCQT could not be significantly predicted by either dimensions of empathy, mood or attitude. The found results imply that empathy and in particular the Fantasy dimension, predicts elaboration and memorisation of the refugee debate even when a statistical control was implemented with the variables mood and attitude.

\subsection{Limitations}

Based on the assumption that empathy is a multidimensional construct (Davis, 1980), the generalisation that the Fantasy Scale directly represents the whole construct of empathy is debateable. Nevertheless, the Fantasy scale represents a dimension of empathy and therefore, it is fair to say that empathy (especially the tendency to put oneself in the thoughts and feelings of others) supports listening attentively to the participants of the refugee debate. For a deeper understanding of how the Fantasy scale can be generalised further investigation would be necessary, especially because there was no experimental manipulation of empathy in this study.

A further point to discuss is in reference to the study's sample as it included almost exclusively people which were recruited at the university campus. Assuming that these participants were students or people working at the university it could be argued they are generally more politically interested in comparison to the general population. Hence, it is possible that there was a bias whilst listening to Frauke Petry due to the possibly higher political awareness of these participants.

A further limitation of the results could be that empathy merely presents a motor for proper listening under certain conditions similar to the relationship of emotional arousal and efficiency in the study of Yerkes and Dodson (1908). Therefore, a very high level of empathy could paralyse helping behaviour and proper listening, caused by high emotional arousal. Furthermore, a middle level of empathy could work as a motor to proper listening, however, it could impede the level of emotional arousal in order to elaborate and memorise properly.

Of particular interest for further investigations would be to implement a manipulation of empathy in an experimental setting to gain a deeper understanding of the influence of empathy on elaboration and memorisation of political debates, in particular with regard to limitations and conditions. For example, do people who feel empathic towards refugees listen specifically to opposite opinions or do they follow the whole debate properly? Additionally, it would be necessary to question whether these people whilst participating in a face-to-face discussion also have advanced elaboration and memorisation of the content. Furthermore, it would be interesting to measure the elaboration and memorisation of political debates in a natural setting. Possibly, the laboratory setting generally leads to people paying more attention when listening to political debates. However, in reality, political debates take place in a natural context with extensive influences from the social environment.

The mood measurement could also be investigated in more detail. For example, instead of measuring the mood with a self-report questionnaire like the PANAS, an objective measurement of the physiological arousal, like the skin conductance, could be used. Therefore, the relationship between empathy and the specific physiological arousal as well as elaboration and memorisation of political debates could be investigated.

Generally, there should be more interdisciplinary investigations of social problems including psychological research. The presented results show the importance of investigating psychological constructs with regard to political contexts. Furthermore, interdisciplinary research should try to implicate practical applications for their findings, as science has the potential to develop and progress important approaches to social and environmental problems.

\subsection{Practical Implications}

In a democracy, it is essential that there are citizens who are politically involved and are able to follow political debates properly in order to ensure a democratic discourse about political issues. The refugee debate in Germany and Europe is showing emotional involvement which plays an important role in this debate. Therefore, and due to the relevance of the refugee debate the results of this study have important practical implications.

The presented results show that empathic feelings towards refugees do not lead to short-sightedness and ignorance of the debate. On the contrary, feeling empathic is an ideal precondition to listening properly to political debates in spite of (or actually due to) parties with even extreme opinions. In this case, empathy is not an antagonist of reason or rationality. They seem to work together; empathic emotions strengthen the personal importance of the topic resulting in listening attentively.

Besides the practical importance of investigations of empathy referring to political context, the investigation of elaboration and memorisation of emotionally charged debates is currently also of particular relevance. Nowadays, there are many political debates that are accompanied by emotion. For example, the political topic of terrorism is ubiquitous in the media. Especially as terrorism is an issue where anxiety quickly spreads throughout society. 
Questions like, how does anxiety influence the elaboration of information or whether the continuous media reporting about terrorism itself influences the elaboration of information are important to examine. Again, interdisciplinary investigations with respect to this topic are necessary.

Additionally, empathy as a psychological construct as well as further psychological constructs referring to political contexts are of specific necessity to investigate.

\section{References}

Anderson, A. K. (2005). Affective influences on the attentional dynamics supporting awareness. Journal of Experimental Psychology: General, 134(2), 258-281. http://dx.doi.org/10.1037/0096-3445.134.2.258

Anderson, A. K., \& Phelps, E. A. (2001). Lesions of the human amygdala impair enhanced perception of emotionally salient events. Nature, 411(6835), 305-309. http://dx.doi.org/10.1038/35077083

Baron-Cohen, S., \& Wheelwright, S. (2004). The empathy quotient: An investigation of adults with Asperger syndrome or high functioning autism, and normal sex differences. Journal of Autism and Developmental Disorders, 34(2), 163-175. http://dx.doi.org/10.1023/B:JADD.0000022607.19833.00

Batson, C. D., Klein, T. R., Highberger, L., \& Shaw, L. L. (1995). Immorality from empathy-induced altruism: When compassion and justice conflict. Journal of Personality and Social Psychology, 68(6), 1042-1054. http://dx.doi.org/10.1037/0022-3514.68.6.1042

Bodenhausen, G. V., Sheppard, L. A., \& Kramer, G. P. (1994). Negative affect and social judgment: The differential impact of anger and sadness. European Journal of Social Psychology, 24(1), 45-62. http://dx.doi.org/10.1002/ejsp.2420240104

Bora, E., Gökçen, S., \& Veznedaroglu, B. (2008). Empathic abilities in people with schizophrenia. Psychiatry Research, 160(1), 23-29. http://dx.doi.org/10.1016/j.psychres.2007.05.017

Cassady, J. C., \& Johnson, R. E. (2002). Cognitive test anxiety and academic performance. Contemporary Educational Psychology, 27(2), 270-295. http://dx.doi.org./10.1006/ceps.2001.1094

Cohen, J. (1988). Statistical power analysis for the behavioral sciences. Hillsdale, New Jersey: Lawrence Erlbaum Associates.

Coke, J. S., Batson, C. D., \& McDavis, K. (1978). Empathic mediation of helping: A two-stage model. Journal of Personality and Social Psychology, 36(7), 752-766. http://dx.doi.org/10.1037/0022-3514.36.7.752

Cuff, B. M., Brown, S. J., Taylor, L., \& Howat, D. J. (2014). Empathy: A review of the concept. Emotion Review, $1-10$.

Davis, M. H. (1980). A multidimensional approach to individual differences in empathy. Catalog of Selected Documents in Psychology, 10, 85.

Davis, M. H. (1983). Measuring individual differences in empathy: Evidence for a multidimensional approach. Journal of Personality and Social Psychology, 44(1), 113-126.

Davis, M. H., \& Franzoi, S. L. (1991). Stability and change in adolescent self-consciousness and empathy. Journal of Research in Personality, 25(1), 70-87. http://dx.doi.org/10.1016/0092-6566(91)90006-C

Decker, O., Kiess, J., \& Brähler, E. (2014). Die stabilisierte Mitte. Rechtsextreme Einstellung in Deutschland 2014 [The stabilized center. Right wing attitudes in Germany 2014]. Retrieved from http://research.uni-leipzig.de/kredo/Mitte_Leipzig_Internet.pdf

Der Bundeswahlleiter. (2016). Ergebnisse der jeweils letzten Landtagswahlen. Retrieved from https://www.bundeswahlleiter.de/de/landtagswahlen/ergebnisse/

Epstein, S. (1991). Cognitive-experiential self-theory: An integrative theory of personality. In R. Curtis (Ed.), The relational self: Theoretical convergences in psychoanalysis and social psychology (pp. 111-137). New York: Guilford Press.

Flüchtlinge $\diamond$ Frontex $\diamond$ Freihandelsabkommen TTIP und CETA. (2016, March 9). 14.000 Flüchtlinge in Idomeni-März 2016 [Video file]. Retrieved from https://www.youtube.com/watch?v=1uDVIj2g-As

Heitmeyer, W. (2005). Deutsche Zustände [German Conditions] (Vol. 3). Frankfurt/M.: Suhrkamp.

Isaacson, W. (1992, December 21). Sometimes, right makes might. In Time (p. 82). 
Johnson, J. D., Simmons, C. H., Jordav, A., Maclean, L., Taddei, J., Thomas, D., ... Reed, W. (2002). Rodney King and OJ revisited: The impact of race and defendant empathy induction on judicial decisions. Journal of Applied Social Psychology, 32(6), 1208-1223. http://dx.doi.org/10.1111/j.1559-1816.2002.tb01432.x

Keller, J., \& Pfattheicher, S. (2013). The compassion-hostility paradox: The interplay of vigilant, prevention-focused self-regulation, compassion, and hostility. Personality and Social Psychology Bulletin, 39, 1518-1529. http://dx.doi.org/10.1177/0146167213499024

Krebs, D. (1975). Empathy and altruism. Journal of Personality and Social Psychology, 32(6), 1134-1146. http://dx.doi.org/10.1037/0022-3514.32.6.1134

Krohne, H. W., Egloff, B., Kohlmann, C. W., \& Tausch, A. (1996). Untersuchungen mit einer deutschen Version der "Positive and Negative Affect Schedule (PANAS)" [Investiation with a german version of the Positive and Negative Affect Schedule (PANAS)]. Diagnostica, 42(2), 139-156.

Phoenix. (2015, November 30). Afd-Parteitag in Hannover: Berichterstattung vom 29.11.2015 [Video file]. Retrieved from https://www.youtube.com/watch? $\mathrm{v}=$ GgVGfwejp2o

Stanghellini, G., \& Rosfort, R. (2013). Empathy as a sense of autonomy. Psychopathology, 46(5), 337-344. https://dx.doi.org/10.1159/000353273

Tsoudis, O. (2002). Influence of empathy in mock jury criminal cases: Adding to the affect control model. Western Criminology Review, 4(1), 55-67.

Vuilleumier, P., Armony, J. L., \& Dolan, R. J. (2003). Reciprocal links between emotion and attention. In R. S. J. Frackowiak et al. (Eds.), Human Brain Function (2nd ed., pp. 419-444). New York: Academic Press.

Watson, D., Clark, L. A., \& Tellegen, A. (1988). Development and validation of brief measures of positive and negative affect: The PANAS scales. Journal of Personality and Social Psychology, 54(6), 1063-1070. http://dx.doi.org/10.1037/0022-3514.54.6.1063

Xu, X., Zuo, X., Wang, X., \& Han, S. (2009). Do you feel my pain? Racial group membership modulates empathic neural responses. The Journal of Neuroscience, 29(26), 8525-8529. http://dx.doi.org/10.1523/JNEUROSCI.2418-09.2009

Yerkes, R. M., \& Dodson, J. D. (1908). The relation of strength of stimulus to rapidity of habit-formation. Journal of Comparative Neurology and Psychology, 18(5), 459-482. http://dx.doi.org/10.1002/cne.920180503

\section{Copyrights}

Copyright for this article is retained by the author(s), with first publication rights granted to the journal.

This is an open-access article distributed under the terms and conditions of the Creative Commons Attribution license (http://creativecommons.org/licenses/by/4.0/). 